\title{
Sustainable Use of Natural Capital: The Inconvenient Imperative
}

\section{Devaka K. Weerakoon}

Senior Professor, Department of Zoology and Environment Sciences, University of Colombo

ABSTRACT
Sri Lanka is a small continental island with an extent of $65610 \mathrm{~km}^{2}$
of which inland waters make up $2905 \mathrm{~km}^{2}$. Further, Sri Lanka has a
maritime area of $517,000 \mathrm{~km}^{2}$ which is almost eight times larger than its
land area. Although a small island, Sri Lanka is endowed with a rich natural
capital. This paper aims to present an overview of the natural assets of
Sri Lanka and their current usage patterns. Based on the current usage
patterns, it can be concluded that many of these assets are not being used
in a sustainable manner and further, that we have failed to realize the full
economic potential with respect to many of these natural resources. This
has resulted due to lack of a planned national approach for the use of Sri
Lanka's natural resources, which may have been abandoned because the
current ad hoc approach is deemed convenient. Finally, this paper stresses
the need for a paradigm shift in our approach towards the use of Sri
Lanka's natural assets, which requires a multi-sectoral needs assessment
and an integrated approach towards achieving these needs. This may not
be convenient as it requires a great deal of planning but is an imperative
if Sri Lanka is to achieve sustainability for its limited and dwindling natural
capital that will provide its citizens the greatest possible benefits.
Natural Capital, Sustainable Use, Sri Lanka, Natural Resources,
Sustainable Development

Suggested Citation: Weerakoon D. K. (2021). Sustainable Use of Natural Capital: The Inconvenient Imperative. University of Colombo Review (New Series III), 2(2), 70 - 87.

(C) 2021 The Authors. This work is licenced under a Creative Commons Attribution 4.0 International Licence which permits unrestricted use, distribution, and reproduction in any medium, provided the original work is properly cited. 


\section{Introduction}

The term capital is used in economics to describe a stock that yields a flow of valuable goods and services. The concept of natural capital was first introduced in 1973 by E. F. Schumacher - a German economist - who wrote a collection of essays titled Small is Beautiful, where he proposed an alternative to the existing thinking of the time - that bigger was better. This idea was further developed by Costanza and Daly, an ecologist and an economist respectively, who founded the trans-discipline called ecological economics (Costanza \& Daly, 1987), where they argued that economics is embedded in the broader ecosystem and not vice versa. Costanza and Daly (1992) further argued that our sustainable future is underpinned by our ability to manage the total natural capital stock at or above the current level.

Humans derive a wide range of goods and services from the natural capital that is broadly referred to as ecosystem services. The value of ecosystem services provided by the natural capital is estimated to be around US\$ 16-54 trillion per year (Costanza et al., 1997). Yet nature is taken for granted as most of the services provided by it cannot be valued effectively and therefore, remain invisible. Natural capital-based approaches demand that setting ecological limits and estimating values for nature are critical to achieve prosperity that is sustainable. However, this is not very convenient as it requires a paradigm shift from the business-as-usual model that has been pursued by most nations thus far. It has now become imperative for policymakers, businesses, and society to recognize that wise use of natural capital underpins the ability to achieve sustainable development and to incorporate natural capital-based approaches to all levels of decision-making. The aim of this paper is to present an overview of how Sri Lanka has fared thus far in its use of natural capital and recommends what must be done in order to ensure sustainable use of natural capital in turn to ensure the prosperity and resilience of the nation.

\section{Natural Capital of Sri Lanka}

Sri Lanka is a small continental island listed as the 25 th largest island in the world (Calder, 2009). Sri Lanka has a terrestrial extent of $65610 \mathrm{~km}^{2}$ of which inland waters make up $2905 \mathrm{~km}^{2}$ (CBSL, 2020) and a maritime area of 517,000 $\mathrm{km}^{2}$ which is almost eight times larger than its land area (Joseph, 2004). Although Sri Lanka is a small island, it is endowed with a rich natural capital, defined as the "stock of natural assets which includes geology, soil, air, water and all living things" (World Forum on Natural Capital, 2021). The following section provides an overview of the natural assets of Sri Lanka, their current level of usage and the issues arising from exploitation.

\section{Geological Resources}

Commercially exploitable geological resources of Sri Lanka include, inter alia, iron ore, clay, sand, silica sand, limestone, gems, graphite, mineral sand, rock phosphate and copper-magnetite (Jayawardena, 1984). Many of these resources are used locally. For instance, the Ceylon Steel Corporation was established in 1961 to utilize the iron ore deposits of Sri Lanka mainly found in the southwestern region of Sri Lanka. 
Clays are used mainly by the ceramic industry to manufacture bricks, tiles, ceramics, glass, and floor tiles (Jayawardena, 1984). Extraction of clay results in large open pits that need to be rehabilitated after extraction is completed. Based on a study carried out in Dankotuwa, Arunashantha and Bandara (2020) report that most of the clay pits are abandoned after extraction, resulting in these pits retaining water during the rainy season, contributing to increase in the population of disease transmitting insect vectors, soil erosion, changes in water quality, visual pollution of the landscape, damage to the riverbanks, and reduction in water quality of the nearby rivers.

Sand is used primarily by the local construction industry and is sourced mainly from riverbeds, coastal sand dunes, and offshore sea sand. High demand for sand has led to overexploitation of river sand that has resulted in significant environmental concerns in almost all the river basins where river sand mining is carried out (Piyadasa, 2011). These include changes in the movement patterns of water and sediment, increased turbidity, lowering of water tables, bank erosion, and lowering of the riverbed leading to increased salinity intrusion. This in turn results in salinization of agricultural land and threatens the quality of drinking water intakes of coastal cities such as Colombo, Kalutara, and Matara. Further, depletion of coastal sand dunes due to sand extraction has made coastal areas more vulnerable to storm surges and tsunamis (Tanaka, 2006). Extraction of sea sand has taken place in the Western Province mostly for reclamation work undertaken in Kerawalapitiya, Port City, and Mount Lavinia beach, and this is likely to undermine the coastline stability in the southwestern region (Kularatne, 2014). Commercially extracted silica sand deposits are located in the Northwestern Province. However, silica sands are underutilized in Sri Lanka as there are no major factories for manufacturing sheet or ornamental glass. The few private glass factories that manufacture bottles have also scaled down their production after the introduction of plastic bottles.

The Miocene limestone deposit that stretches as a narrow belt from Puttalam to Jaffna is used mainly for cement production. Limestone extraction for cement manufacture was commenced in 1950 with the establishment of the Kankesanthurai Cement Factory and a second factory was subsequently established in Puttalam in 1971 in a limestone quarry in Aruwakkalu. The plant at Kankesanthurai was closed down in 1991, while Puttalam Cement Company was privatized in 1993 and is currently operated by Thai Siam City Cement Company. Thus, the only operational limestone quarry in Sri Lanka is located in Aruwakkalu. Limestone quarrying involves opening up a section of the limestone deposit and extracting the subsurface limestone. Once the extraction is completed the quarry operation will move to a new section. Establishment of the quarry site results in removal of vegetation and the soil layer overlying the limestone deposit. Therefore, limestone extraction results in a number of negative impacts, such as the loss of both above ground and below ground biodiversity associated with the site, emission of dust, noise and vibration, increased soil erosion, and sedimentation of surface water bodies (Kumarasinghe, 2013). Once the extraction of limestone is completed, the quarry site remains as a barren land unless the site is properly rehabilitated, as it is devoid of topsoil for plants to regrow. Initially, under Puttalam Cement, there was no rehabilitation work after the termination of 
quarrying and these abandoned quarry sites remain as barren lands even to date. However, once the operation was taken over by Holcim Cement, rehabilitation of quarry sites used by them was undertaken in 2002 and this practice continues to date even under its new management by Thai Siam City Cement Company. However, another international mining company based in Australia (Iluka) has shown an interest in extracting minerals found in the soil overlying the Aruwakkalu limestone deposit. This would result in the disturbance of the restored areas again. This is a classic example of unplanned development: ideally, a section of the deposit should be demarcated and the minerals in the soil should be extracted first, followed by extraction of the limestone deposit underneath the soil layer followed by restoration of the mined section, not the reverse as might happen should Iluka be given permission to mine.

Sri Lanka also exports a number of its mineral resources. The gem industry is the oldest industry in Sri Lanka dating back to the 1st and 2nd Centuries. Gem mining is carried out mainly in the Rathnapura district, while gems have also been found in several other districts such as Polonnaruwa, Nuwara Eliya, Badulla, and Moneragala. Gem extraction also involve washing of soil that releases large quantities of sediment to the stream network and this has a detrimental effect on stream dwelling species. Further, because more than $75 \%$ of the endemic fish in Sri Lanka is found in stream networks that are affected by the gem mining industry, the increased sedimentation is considered as a major threat to the longterm survival of many threatened and endemic freshwater fish in Sri Lanka (Goonatilake, 2020).

Graphite is the second oldest mineral resource exploited in Sri Lanka, next to gems. The industry dates back to 150 years and involves mining and export of high-grade graphite. Sri Lanka holds less than 5\% of the global graphite reserves. However, the carbon content of Sri Lankan graphite is more than 95\%, which makes it one of the best graphite suitable for production of graphene. Even though Sri Lankan graphite is considered to be of highest quality, the graphite industry has been limited to extraction and export of graphite until 2018, where Ceylon Graphene Technologies has been established with the aim of placing Sri Lanka in the global market for graphene and associated products. This example can be followed for the rest of the major mineral resources, which are currently exported as raw material rather than value-added products (e.g., mineral sand and rock phosphate), which will bring better economic returns to the nation.

The mineral extraction sector in Sri Lanka also needs significant improvements to convert it into a sustainable industry. One of the main issues owing to mineral extraction is the lack of adequate regulations on post extraction rehabilitation of the mining sites. Further, most of the mineral resources are located beneath the soil surface and extraction of the resource results in the removal of surface vegetation and soil, that has led to loss of biodiversity, increase in soil erosion, sedimentation of surface water bodies, erosion of riverbanks, and lowering of riverbeds leading to increased saltwater intrusion that will be exacerbated by the predicted climate change driven sea level rise. Mineral extraction also contributes to several social issues, of which the main issue is the conflict between this activity and the livelihoods of people. For instance, mineral sand deposits are found mainly 
in the coastal zone, which are also utilized by fisher communities, and extraction of mineral sands therefore will deprive them from using the beaches. Further, fisher communities that are inhabiting the land that overlies the deposit are required to be resettled. Ideally lands that are identified as having valuable mineral resources should be demarcated and declared as reserves, and they should not be used for development or resettlement until such time the mineral resources are extracted. Further, there should be a long-term plan to extract these mineral resources and rehabilitate the land, which can then be used for resettlement or any other purpose so that conflicts with land use can be avoided altogether. Finally, the contribution of minerals from Sri Lanka to the global market is relatively very low (less than $1 \%$ ) and therefore, exporting raw minerals will have relatively low economic returns compared to value-added products, which will not only result in higher economic returns but also uplift local industries and create new job opportunities (Subasinghe et al., 2021).

\section{Soil Resources}

Weathering is the process that is responsible for the formation of soil, which is governed by physical processes such as solar radiation, wind, and water and assisted by plant roots and microorganisms that inhabit the soil (collectively referred to as the soil biodiversity or below-ground biodiversity). Soils provide many essential ecosystem services in both natural and human-made ecosystems, such as providing a medium for plants to grow; sequestering carbon and thereby influencing the regulation of climate; providing a habitat for soil-dwelling organisms; facilitating water cycling; recycling of nutrients; filtering and purifying water; as well as providing a base for the construction of infrastructure (Baveye et al., 2016). There are 14 major soil types in Sri Lanka, of which Reddish Brown Earths (RBE), Red Yellow Podzolic (RYP) and Low Humic Gley (LHG) soils are the most abundant types (Panabokke, 1996).

Agriculture practices in Sri Lanka date back to 15500 BC according to Premathilake (2006). These practices expanded during the period of hydraulic civilization that spanned nearly 2000 years, and this resulted in the extensive remodeling of natural habitats in the dry zone, as evidenced by the wide distribution of manmade reservoirs built during the hydraulic civilization to facilitate agriculture. During the latter part of the colonial period much of the lands in the wet and intermediate zones were converted to large monocultures of tea, rubber, and coconut, while the dry zone forests were reestablished as the population center shifted to the wet zone. After independence was regained, the focus shifted again to the dry zone. During the last century alone nearly $40 \%$ of the forest cover in Sri Lanka has been lost, due to conversion of forests to croplands mainly under the accelerated Mahaweli Development Project (Fernando et al., 2015). At present nearly two thirds of the land extent of Sri Lanka is used for agriculture.

In the mid-20th Century, traditional agriculture which was based mainly on organic inputs was transformed to modern agriculture, with a heavy dependence on inorganic fertilizer and crop cultivars, which were responsive to high inorganic inputs that enhanced agricultural productivity. Initially this resulted in a significant improvement in agricultural productivity, as the soils were able to retain the inorganic fertilizer because 
of their high organic content. However, over the years, agricultural practice with heavy dependence on inorganic fertilizer with no supplementation of the soil organic matter has led to degradation of overall soil fertility, leading to dead soils requiring incrementally high inputs of inorganic fertilizer with time. According to the current estimates, soil fertility has declined in $61 \%$ of the arable lands and $44 \%$ of the agriculture lands show some form of degradation. The key drivers that have contributed to land degradation in Sri Lanka include erosion, nutrient depletion, heavy metal accumulation, salinization, acidification, ground water contamination, and landslides (Dharmakeerthi \& Wicramasinghe, 2015).

One of the key determinants of soil fertility is the richness of the soil microbiome. Plant roots secrete energy-rich carbon sources that are used by both free living microbes in the vicinity of plant roots and symbiotic microbes that are linked to plants roots via beneficial fungi. These microbes in turn will increase the availability of minerals and trace elements required to maintain the health and vitality of their plant hosts. Microbial activity also promotes soil aggregation which enhances soil structural stability, aeration, infiltration, and water-holding capacity (Dubey et al., 2019). Modern farming methods that rely heavily on agrochemicals have compromised the soil microbiome, resulting in a significant reduction in soil carbon, which in turn reduces the productive potential of the land and the profitability of farming. This has also led to a reduction in the availability of soil nutrients, which in turn has reduced the amount of minerals and trace elements present in the food of both humans and farm animals. In addition to the decline in nutrient levels, the loss of soil fertility has brought about significant changes in the mineral ratios. Since critical ratios of minerals and trace elements are a necessity for optimum physiological function, soil dysfunction affects wellbeing of both humans and farm animals. Further, dead soils with little or no organic matter cannot retain the chemicals applied, and the uptake of nutrients by plants in such soils is also inefficient, as the microbes that facilitate nutrient uptake are missing or poorly represented in such impoverished soils (Kulasooriya, 2021). More than two thirds of the fertilizer applied to such soils are carried by surface runoff during heavy rains into surface water bodies, resulting in eutrophication. Therefore, Sri Lanka must take immediate steps to restore its impoverished soils. This requires a planned approach to improve the structure, microbiome, nutrient, and overall carbon levels of the soil, which cannot be achieved overnight. The present government has imposed a total ban on import of inorganic fertilizer with the aim of addressing this issue. However, such an abrupt move, without adequate alternatives in place, will lead to large scale crop losses that will drive the farmers away from sustainable agriculture and seriously undermine the food security of the nation (Beillard \& Galappattige, 2021).

\section{Air Resources}

Air is a critical resource for all living organisms that inhabit Earth. Since the latter half of the 20th Century, people spend more time indoors, and therefore, maintaining both indoor and outdoor air quality is an important consideration. Hence, managing both indoor and outdoor air resources are critical to ensure human health and well-being. Air quality monitoring during the period 1997-2003 indicates that the levels of sulphur 
dioxide, nitrogen dioxide, and ozone are steadily increasing. Deterioration of outdoor air quality in Sri Lanka can be ascribed to the increase in the number of motor vehicles, traffic congestions, open burning of waste, biomass burning, and emissions from industries and refineries. Poor indoor air quality is the result of emissions from cooking, burning of mosquito coils and incense sticks, and in more recent times, the increase in microplastic in both indoor and outdoor air (Ileperuma, 2020). Recognizing the growing problem in air quality, the government of Sri Lanka developed an action plan in 1993, referred to as Clean Air 2000. Further, the Air Resource Management Center (AirMAC) was established for policy development, creating awareness, setting standards for air quality management, and monitoring of air quality. An Air Resource Management and Monitoring Unit (ARM\&M) has also been established in the Central Environmental Authority to ensure that ambient air quality is managed, aligned with national environmental regulations (CEA, 2021). During the last decade, several positive steps have been taken to improve air quality that include making emission testing mandatory for vehicles, imposing a ban on importing vehicles older than four years, switching to lead-free high-octane fuels, increasing the contribution by renewable sources to the national grid, formulating a cleaner production policy, and establishing a National Cleaner Production Center. However, some of the policy decisions taken by successive governments such as the removal of incentives for hybrid and electric vehicles, and the cancellation of the light rail project have contributed negatively towards achieving air quality targets. Further, Sri Lanka has failed to make substantial progress towards expanding the public transport system, facilitating non-motorized transport, introducing economic or incentive-based instruments to promote pollution control technologies, and monitoring and regulating industries that emit volatile pollutants - all of which are essential steps towards ensuring outdoor air quality.

\section{Water Resources}

Planet Earth is considered a blue planet because $70 \%$ of its surface is covered with water. Water, like air, is essential for all living organisms. Another unique feature of Earth is that water exists in all its three possible physical forms - solid, liquid, and gas - which made life possible on the planet. Life evolved and flourished in water for nearly four billion years, before colonizing the land about 470 million years ago (Heckman, 2001). For four billion years, the terrestrial surface of the planet was comprised mainly of rock that was exposed to erosive forces, which resulted in minerals contained in the rocks to be released and washed into the oceans. As a result, salts accumulated in the oceans for much of the history of the planet, which makes water in the oceans have a high salt content (salt water) compared to water on land (freshwater) while mixing of salt water and freshwater at interphases such as estuaries and lagoons forms brackish water. Sri Lanka, being an island, is endowed with all three forms of water.

The freshwater resources of Sri Lanka can be categorized broadly into surface and ground water. Surface water resources extend over $4 \%$ of the land extent (CBSL, 2020) and comprise both natural and manmade systems. Natural freshwater sources include rivers, villus, and marshes, while the manmade systems include ponds, irrigation canals, and a 
large number of small, medium, and large reservoirs. A further $9 \%$ of Sri Lanka's land extent comprises rice paddy that retains water over much of its growth cycle. Rainfall is the main source that feeds both surface and ground water resources which are respectively estimated to be around $44000 \mathrm{MCM}$ and $7800 \mathrm{MCM}$ annually (Imbulana et al., 2006). The current per capita internal renewable freshwater resource availability is around $2500 \mathrm{~m}^{3}$, which ranks Sri Lanka 95th among 179 countries (World Bank, 2021).

Sri Lanka has a long history of water resource development, which dates back to the 4th Century BC where the first tank, Abhaya Wewa (currently called Basawakkulama), was built by King Pandukabhaya, and continues to provide water for inhabitants of Anuradhapura to date. From $400 \mathrm{BC}$ to 1200 AD, more than 30,000 reservoirs have been built by successive kings, heralding a great era in the history of Sri Lanka referred to as the hydraulic civilization. During this period, almost all the river basins in the intermediate and dry zone were developed to facilitate irrigated agriculture. Over centuries, Sri Lankan reservoir builders fine-tuned the technology to make it one of the most useful human constructs that is considered as the hallmark of ancient Sri Lankan hydro-engineering. After independence, Sri Lanka continued with the irrigated agriculture model, resulting in the establishment of large irrigation schemes such as Gal Oya (1948) and Udawalawe (1967) and renovation of most of the abandoned reservoirs in the dry zone. The Accelerated Mahaweli Development Scheme - initiated in the late $1960 \mathrm{~s}$ - is perhaps the most ambitious irrigation development project undertaken by Sri Lanka, resulting in water resource development of Mahaweli river and many other major river basins such as Kala Oya, Malwathu Oya, Yan Oya, and Maduru Oya, continuing to date. In addition, water resources are harnessed for hydropower generation, with major hydropower projects located mainly in Kelani river and Mahaweli river and more than 300 mini hydro projects scattered across most of the river basins in the wet and intermediate zones (Silva \& Silva, 2016). Water resources are also used for drinking as well as other industrial projects.

These river diversions, whilst providing multiple benefits to the nation, have led to a wide range of social and environmental impacts such as changes in species distribution and abundance, loss of biodiversity, genetic isolation of species through habitat fragmentation, alteration of aquatic habitats, reduction in transport of silt and nutrients to sustain the activities of the river mouth, incursion of salinity from the sea, loss of floodplain fisheries, lack of water for downstream users, loss of aesthetic beauty due to drying of waterfalls, and loss of revenue from tourism and other recreational activities. A recent strategic environmental assessment conducted to evaluate the cumulative impact of 67 planned irrigation projects planned to be implemented during the next few decades indicates that implementation of the proposed projects will result in the loss of $2 \%$ of forest cover, loss of $1.5 \%$ of protected areas, escalation of human-elephant conflict in 40 out of the 67 project areas, changes in brackish water ecosystems, relocation of 9000 households, and loss of 15600 ha of lands that are cultivated at present (MIWRM, 2018). In parallel, these projects will enhance paddy production by one million metric tons, increase production of inland fishery by 25,000 metric tons, add $650 \mathrm{GWh}$ of energy annually to the national grid, provide 300 million $\mathrm{m}^{3}$ of drinking water, create many recreational opportunities, and contribute 
to significant improvements of infrastructure. Water resource development in the future should be carefully planned and prioritized using multi-criteria assessment tools to ensure that the nation can achieve the desired development targets while losing the minimum amount of natural capital.

There are six main types of groundwater aquifers identified in Sri Lanka. Groundwater is used extensively for domestic, commercial, and industrial purposes. The dependence on ground water is higher among the rural population (80\%) compared to the urban population (Panabokke \& Perera, 2005). Ground water is used for farming, especially during the dry periods, which has resulted in intensive use of shallow groundwater. People in the Jaffna peninsula depend heavily on its ground water resources, leading to overexploitation of groundwater resources, which in turn has increased saltwater intrusion. Further, there is a significant imbalance in the draw-off and recharge rates, indicating the need for proper management of ground water utilization (Gunaalan et al., 2018).

Coastal lagoons and estuaries are the main brackish water containing bodies in Sri Lanka. The $1,340 \mathrm{~km}$ long coastline supports 82 lagoons that vary in size between 0.016 $\mathrm{km}^{2}$ (Kirinda Lagoon) to $441 \mathrm{~km}^{2}$ (Jaffna Lagoon) (Silva et al., 2013). In addition, there are 103 river basins, of which $80 \%$ open directly to the sea, forming estuaries, while the rest open into lagoons. These lagoons and estuaries create an ecotone from the ocean to land and therefore, house a mosaic of habitats such as salt marshes, mangroves, sea grass beds, mud flats, barrier islands, beaches, sand spits, and sand dunes (Miththapala, 2013). These natural habitats support a diverse assemblage of plants and animals that provides a wide range of ecosystem services (Amarasinghe, 1997). Lagoons and estuaries serve as refuges for many commercially important fish and shellfish, as they function as feeding grounds, breeding grounds, or nurseries, and therefore play an extremely important role in the sustenance of coastal fisheries, supporting around 200,000 fishers (MFARD, 2019) as well as providing anchorage for their vessels (Samarakoon \& Samarawickrama, 2012). Further, lagoons and estuaries serve as a buffer against coastal hazards such as storm surges and floods, and help protect the coastline as well as offshore habitats such as coral beds by trapping sediments that are carried by surface runoff. Finally, lagoons and estuaries provide opportunities for recreation and tourism development.

These brackish water systems, by design, function as portals between the land and ocean and most of the rainfall runoff passes to the ocean via these systems. As a result, these systems are exposed to high loads of land-based pollutants arising from improper solid waste disposal, release of untreated or partially treated industrial effluents, and chemicals applied to agriculture fields. Some of these pollutants - such as heavy metals, organochlorides, and polycyclic aromatic hydrocarbons - are bioaccumulated through brackish water food chains, eventually reaching humans when they consume fish or shellfish. Many of the lagoons and estuaries are encroached by people who release their sewage and wastewater directly into these water bodies, resulting in eutrophication of lagoons and estuaries. Lagoons are considered as ephemeral systems (Silva et al., 2013) and their longevity is defined by activities that take place in their drainage basins. Deforestation and other improper land uses result in excess erosion that will increase the sediments reaching the lagoon, which 
may lead to rapid infilling of the lagoon and reduction in lagoon extent. A classic example is the Negombo lagoon which has undergone significant reduction during the last two decades because of rapid urban expansion and excess sediment inflows (Athukorala et al., 2021). Expansion of aquaculture, especially shrimp farming, has a significant impact on brackish water ecosystems, especially mangroves in the Puttalam district (Bournazel et al., 2015). Further, salt production has also resulted in conversion of productive brackish water ecosystems in the Puttalam, Hambantota, and Trincomalee districts. Therefore, these lagoons and estuaries should be carefully managed to ensure that they are maintained in an optimum state to provide maximal benefits and especially protected from the predicted climate change driven hazards.

Brackish water systems depend on a balance of inflows of salt water and freshwater. Any change in the water regimen, which can arise from river diversion, may increase or decrease freshwater inflows and thereby change the salinity of the lagoon. A case in point is the Bundala National Park which comprises five lagoons. It has also been designated as an International Man and Biosphere Reserve (2005) and is the first Ramsar Site in Sri Lanka (1990). In 1992, the Kirindi Oya irrigation settlement project was established by diverting water from Kirindi Oya via the Lunugamvehera reservoir to the drainage basin of the lagoons of Bundala National Park, changing the salinity of the brackish water lagoons, converting them, over time, to freshwater bodies. The accompanying changes in the food webs of the lagoons resulted in the conversion of bird assemblages of these lagoons, which were dominated by large numbers of migrant species, into a more native freshwater bird assemblage, reducing its appeal as a Ramsar Site (Bellio, 2011). This is just one example that bears evidence to the fact that Sri Lanka has not managed its brackish water ecosystems in a sustainable manner and thereby has driven most of these ecosystems to a state of degradation, depriving our ability to accrue the critical ecosystem services provided by them.

The extent of the sea around the island of Sri Lanka is almost eight times its land area. Even though the ocean around us is endowed with rich resources, our ocean based economic activities are limited to traditional industries that have persisted over decades such as fisheries, tourism, and salt production. The marine sector accounts for $82 \%$ of the annual fish production and $90 \%$ of this production comes from near shore fishers, while the multi-day fleet that carry out fishing in deep seas makes up only $10 \%$ of the total fishing fleet (Ministry of Fisheries, 2020). Thus, Sri Lanka is overexploiting the coastal fisheries resource, while much of the fish resource in the deep sea remains underutilized. Traditionally, the tourism industry has promoted the sea and sand experience with very little value addition, by introducing other types of tourism experiences such as surfing, diving, sea sports etc., which are carried out in a very small scale compared to other countries in Asia. Salt production and mineral sand extraction discussed earlier are the other major industries that utilize the marine natural capital.

The concept of the "blue economy" was conceived at the Rio+20 United Nations Conference on Sustainable Development, held in Rio de Janeiro in June 2012, to encourage countries to sustainably use their marine resources for economic development. Even though 
successive Sri Lankan governments integrated the concept of blue economy into their policy framework (PEC, 2019 and SLPP Manifesto 2019), very little has has been done to promote the concept at a national level. It should also be noted that nearly $50 \%$ of the fish caught are discarded either because they are by-catch or not suitable to be sold (Jones et al., 2018). No attempts have been made thus far to convert fish offal to value-added end products such as animal feed, fertilizer, fish oil, fish-skin leather, collagen, gelatin, chitin or chitosan (from crab shells and shrimp waste), or natural calcium (from shellfish) that can help Sri Lanka to mainstream the concept of blue economy.

\section{Living Resources}

Although Sri Lanka is a small island, it has a wide variety of climatic, topographic, and soil conditions, which has given rise to a diverse array of aquatic and terrestrial habitats. Historically, Sri Lanka was part of the ancient Gondwanaland and was located adjacent to the African continent. Around 130 million years ago, the Deccan plate - which consisted of India and Sri Lanka - broke away from Gondwanaland, drifted northwards and collided with the Asian plate around 43 million years ago (McLoughlin, 2001). Thereafter, Sri Lanka separated from India about 8,000-10,000 years ago, due to submersion of the land bridge between the two countries (Katupotha, 1993). These zoogeographic, climatic, topographic, and edaphic factors have shaped the species diversity of Sri Lanka, supporting an unusually high biodiversity compared to other small-sized tropical islands. The hallmark of Sri Lanka's biodiversity is the presence of large populations of megafauna (asian elephant, leopard, sloth bear etc.,) that do not occur in other small-sized islands as well as a large proportion of endemic species (MoMD\&E, 2016).

Therefore, Sri Lanka along with the Western Ghats of India is listed as one of the 36 biodiversity hotspots of the world (Conservation International, 2021). In addition, the biodiversity of Sri Lanka is globally recognized with 82 Key Biodiversity Areas (Birdlife International, 2021a), 70 Important Bird Areas (Birdlife International, 2021b), two UNESCO natural World Heritage sites (UNESCO, 2021a), six Wetlands of International Importance (Ramsar, 2021) and four International Man and Biosphere Reserves (UNESCO, 2021b). However, many of the endemic species in Sri Lanka are listed as Globally or Nationally Threatened because of a suite of anthropogenic drivers. These can be categorized broadly into those that influence habitats (loss, degradation, fragmentation, and conversion) and species (spread of alien invasive species, human-wildlife conflict, and overexploitation) (MOE, 2012). The impact of these drivers will be exacerbated due to climate change driven processes.

Historical records and fossil evidence suggests that much of Sri Lanka has been covered with forests during prehistoric times. These forests have been subjected to significant remodeling, at first, by natural forces such as climate change and then by landuse changes brought about by humans during the last 2,000-3,000 years. As Sri Lanka's civilization is based on agriculture, there has been extensive remodeling of natural habitats, first in the dry zone during the height of the hydraulic civilization, then in the wet zone 
during the late colonial period and, after independence was regained in 1948, the focus has shifted to the dry zone again. During the last century alone nearly $40 \%$ of the forest cover in Sri Lanka has been lost due to conversion of forest to croplands. At present Sri Lanka continues, annually, to lose an estimated 7,000 hectares (Fernando, et al., 2015).

The current extent of Sri Lanka's forest cover is estimated to be around 2 million ha, which is approximately $29 \%$ of its terrestrial area. However, the extent of closed canopy or dense forest is estimated to be around 1.5 million ha. In addition to the 7,000 ha of forest loss per annum, an estimated 25,000 ha of forest land has been released for development purposes during the last five years (MIWRM, 2018). Based on the development projects that are in the process of being planned or developed, more lands within the protected areas will have to be released to make way for development (MIWRM, 2018). In November 2020, the national government issued a circular (MWFC/1/2020) repealing two previous circulars $05 / 2001$ (a circular issued to transfer the management of all remaining forests under the category of "other state forests" from Divisional Secretaries to Forest Department) and 02/2006 (an addendum to 05/2001, which provided a pathway for the Divisional Secretaries to identify non forest lands for development and exempt them from the jurisdiction of Forest Department). An estimated 300,000 ha designated as "other state forests" and an equal extent of forest lands not under formal protection will be lost because of this action. This will result in the loss of biodiversity in these forests, critical ecosystem services provided by these forests, and the escalation of human-wildlife conflict (Samarasinghe et al., 2021). Further, this circular completely contradicts the environmental policy of the national government, which pledged in their manifesto, Vistas of Prosperity and Splendour to increase the forest cover of Sri Lanka to $30 \%$. Instead, this circular will result in an overall loss of forest cover by about $5 \%$. This short-sighted approach is an example of the classic dichotomy between commitment and practice shown by successive governments of Sri Lanka, who have not only failed to honor commitments made nationally but also globally, as can be seen in the case of Sri Lanka's commitment, under the Paris Agreement of 2015 , to increase its forest cover to $32 \%$.

The global climate, which is changing rapidly, is considered the main global driver of change, especially for biodiversity. Climate change magnifies existing threats, for example, by potentially increasing the distribution and abundance of introduced plants and pest animals already found in Sri Lanka. It is also likely to trigger new threats, including long-term changes in rainfall and temperature patterns; rising sea levels; and changes to the frequency and severity of extreme events such as landslides, forest fires, floods, and droughts. These changes can accelerate the rate of extinctions and disrupt ecological processes throughout the 21 st Century and beyond. As a tropical island, Sri Lanka is extremely vulnerable to the predicted climate change related impacts, such as sea level rise, saltwater intrusion leading to increased salinization of low-lying areas, rising ocean temperatures and ambient temperatures, changes in rainfall patterns, and increased frequency of storms and other natural hazards such as floods and landslides. The forests are the first line of defense against these predicted changes as they can act as carbon sinks as well as buffers against climate change driven hazards. 
The existing legal and sectoral policy framework comprising the Constitution, laws, and policies adequately support biodiversity conservation. However, there are serious gaps in law enforcement and policy implementation. Like laws and policies, institutional mandates, visions, and missions of agencies overlooking biodiversity conservation are well formulated to support biodiversity conservation. However, poor institutional coordination and collaboration for biodiversity conservation at the national as well as sub-national levels, is one of the main weaknesses that precludes integration of biodiversity conservation into sectoral and cross-sectoral plans and programmes of relevant line agencies, as well as integration into development and fiscal policies, financial planning, and the overall financial system in general. Another barrier is that biodiversity receives low attention among key government policy makers, financial experts, top level administrators, bankers, and business leaders. This has led to low priority for investments in biodiversity conservation and sustainable use of bio-resources. This is caused by inadequate awareness of the immense potential offered by Sri Lanka's biodiversity for economic growth. Therefore, Sri Lanka has a long way to go to achieve the goal of integrating ecosystem and biodiversity values into local and national level planning and decision making.

\section{Towards Achieving a Delicate Balance between Use of Natural Capital and Economic Development}

There is a strong link between economic development and sustainable use of natural capital. The growth of a country depends on efficient conversion of its natural capital into economic capital, which in turn can be used to build social capital by reducing poverty, through investing on education and infrastructure (Costanza \& Daly, 1992). Many affluent countries have reinvested a part of the economic capital into building natural capital by restoring degraded ecosystems. However, many developing countries have failed to do the same, resulting in rising poverty levels and further degradation of natural capital. Even if economic and social capital continue to grow, the resilience and sustainability of these capitals will be undermined by the loss of natural capital. Therefore, without natural capital it will become increasingly difficult to cope with the emerging global challenges such as climate change, growing world population resulting in increased demands for food as well as other essential resources, and increased levels of pollution.

Sri Lanka, though a small island, has a relatively high human population, which has required an investment in many large-scale development projects. Sri Lanka's economy depends heavily on agriculture, and agricultural expansion is one of the major drivers of biodiversity loss. Thus, conversion of forests into croplands will result in loss of critical ecosystem services, making Sri Lanka more vulnerable to climate-change driven adverse impacts. For instance, deforestation of the catchment areas will affect the flow regimes of the rivers, where during the rainy season, there is high water flow in the rivers resulting in floods and during the dry season, rivers dry out causing droughts. Both of these conditions will have a direct negative effect on agriculture as well as other economic activities such as hydropower generation, beverage production, and provision of safe drinking water that depends on a regular flow in the rivers. Further, loss of forests will lead to loss of habitat, 
forcing many wild animals to enter into human use areas that leads to an escalation of the human-wildlife conflict. While the loss of forests will have a significant negative impact on agricultural production, it will intensify conflict, pushing animals towards the brink of extinction because of increased mortality of these animals caused by humans. For an example, Sri Lanka annually loses more than 400 elephants due to the human-elephant conflict (Prakash, 2020), even though elephants are one of the key tourist attractions in Sri Lanka. Therefore, the current development strategy followed by Sri Lanka cannot be termed sustainable, as it results in the loss of critical natural assets and at the same time preventing the accrual of full benefits of its investments and the achievement of its longterm development goals. Therefore, Sri Lanka needs a paradigm shift in its approach to development, where current approaches are replaced with novel, innovative, nature-based solutions that will ensure sustainability

Even though successive governments have made pledges towards the sustainable use of natural capital, their actions have not supported their commitments. Instead, they have chosen the convenient way of focusing simply on improving gross domestic product, the standard measure of economic well-being, by liquidating the natural capital. This is a poor strategy, as it will prevent the achievement of sustainable development. This can be attributed to the lack of a proper national policy for utilization of Sri Lanka's natural resources. Formulation of such a policy must have been ignored since the current adhoc approach has been deemed convenient. Therefore, solving this dichotomy between commitments and actual practice is essential, if Sri Lanka is to achieve the sustainable development goals, which, in turn, is underpinned by our ability to use its limited and dwindling natural capital wisely. Thus, a paradigm shift in our approach towards use of Sri Lanka's natural assets is required urgently. It is no longer a choice but an imperative if citizens of Sri Lanka are to accrue the maximum benefit from Sri Lanka's natural capital.

\section{References}

Amarasinghe, M. D. (1997). Ecological functions of mangrove and related ecosystems and their contribution to economic sustainability. Sri Lanka Journal of Aquatic Science, 2, 1-20.

Arunashantha, S., \& Bandara, S. M. R. S. (2020). The environmental impact of the clay industry in Sri Lanka: With special reference to Dankotuwa Divisional Secretariat Division (DSD). International Journal of Scientific and Research Publications, 10(7), 92-96.

Athukorala, D., Estoque, R. C., Murayama, Y., \& Matsushita, B. (2021). Impacts of urbanization on the Muthurajawela Marsh and Negombo Lagoon, Sri Lanka: Implications for landscape planning towards a sustainable urban wetland ecosystem. Remote Sensing, 13(2), 316. https:// doi.org/10.3390/rs13020316

Baveye, P. C., Baveye, J., \& Gowdy, J. (2016). Soil “ecosystem" services and natural capital: Critical appraisal of research on uncertain ground. Frontiers in Environmental Science, 4, 41. https://doi. org/10.3389/fenvs.2016.00041 
Beillard, M. J., \& Galappattige, A. (2021). Sri Lanka restricts and bans the import of fertilizers and agrochemicals [Unpublished report]. United States Department of Agriculture.

Bellio, M. G. (2011). Agricultural development and impacts on wetlands: Trade-offs for waterbird conservation in Sri Lanka [Unpublished doctoral dissertation]. University of New South Wales, Australia.

Birdlife International. (2021a). KBA Dashboard. Retrieved from https://maps.birdlife.org/portal/ apps/opsdashboard/index.html\#/754b32566bfa4f23ba7fa67942684553

Birdlife International. (2021b). Sri Lanka. http://datazone.birdlife.org/country/sri-lanka/ibas

Bournazel, J., Kumara, M. P., Jayatissa, L. P., Viergever, K., Morel, V., \& Huxham, M. (2015). The impacts of shrimp farming on land-use and carbon storage around Puttalam lagoon, Sri Lanka. Ocean \& Coastal Management, 113, 18-28. https://doi.org/10.1016/j.ocecoaman.2015.05.009

Calder, J. (2009). Largest islands of the world. Worldislandinfo.com. Retrieved July 20, 2021, from http://www.worldislandinfo.com/LARGESTV1.html

Central Bank of Sri Lanka. (2020). Economic and social statistics of Sri Lanka. Statistics Department, Central Bank of Sri Lanka.

Central Environmental Authority. (2020). Air resource management and monitoring unit: Introduction. http://www.cea.lk/web/en/2013-05-07-07-51-07/environmental-pollution-contorldivision/air-quality-unit

Circular No. 5/2001 of 10 August (2001) on "Assignment of Management and Control of all other State Lands with the Conservator General of Forests" of the Secretary to the Ministry of Forest Resources and Environment. Sri Lanka.

Circular No. 02/2006 of 17 May (2006) on "On assigning the non-forest lands among the other forest lands entrusted with the Conservator General of the Forests to Divisional Secretaries" of the Secretary to the Ministry of Forest Resources and Environment. Sri Lanka.

Circular No. MWFC/1/2020 of 4 November (2020) on "Management of other state forests" Ministry of Wildlife and Forest Conservation. Sri Lanka.

Conservation International. (2021). Biodiversity hotspots: Targeting investment in nature's most important places. https://www.conservation.org/priorities/biodiversity-hotspots

Costanza, R., \& Daly, H. (1987). Toward an ecological economics. Ecological Modelling, 38(1-2), 1-7. https://doi.org/10.1016/0304-3800(87)90041-X

Costanza, R., \& Daly, H. (1992). Natural capital and sustainable development. Conservation Biology, 6(1), 37-46. https://doi.org/10.1046/j.1523-1739.1992.610037.x

Costanza, R., d'Arge, R., de Groot, R., Farberk, S., Grasso, M., Hannon, B., Limburg, K., Naeem, S., O’Neill, R. V., Paruelo, J., Raskin, R. G., Sutton, P. \& van den Belt, M. (1997). The value of the world's ecosystem services and natural capital. Nature, 387, 253-260. https://doi. org/10.1038/387253a0 
Dharmakeerthi, R. S. \& Wicramasinghe, W. D. (2015). Status and national priorities of soil resources in Sri Lanka [Presentation extract]. For 2015 International Year of Soils.

Dubey, A., Malla, A. M., Khan, F., Chowdhary, K., Yadav, S., Kumar, A., Sharma, S., Khare, P. K. and Khan, M. L. (2019). Soil microbiome: A key player for conservation of soil health under changing climate. Biodiversity and Conservation, 28, 2405-2429.

Fernando, S., Senaratna, A., Pallewatta, N., Lokupitiya, E., Manawadu L., Imbulana, U., De Silva, I., \& Ranwala, S. (2015). Assessment of key policies and measures to address the drivers of deforestation and forest degradation in Sri Lanka. Sri Lanka UN-REDD Programme. https://doi. org/10.13140/RG.2.2.15886.15688

Goonatilake, S. De A., Fernando, M., Kotagama, O., Perera, N, Vidanage, S., Weerakoon, D., Adam A., \& Maiz-Tome L. (2020). The national red list of Sri Lanka: Assessment of the threat status of the freshwater fishes of Sri Lanka. International Union for Conservation of Nature, Sri Lanka and the Biodiversity Secretariat, Ministry of Environment and Wildlife Resources.

Gunaalan, K., Ranagalage, M., Gunarathna, M. H. J. P., Kumari, M. K. N., Vithanage, M., Srivaratharasan, T., \& Warnasuriya, T. W. S. (2018). Application of geospatial techniques for groundwater quality and availability assessment: A case study in Jaffna Peninsula, Sri Lanka. International Journal of Geo information, 7(1), 20. https://doi.org/10.3390/ijgi7010020

Heckman, D. S., Geiser, D. M., Eidell, B. R., Stauffer, R. L., Kardos, N. L., \& Hedges, S. B. (2001). Molecular evidence for the early colonization of land by fungi and plants. Science, 293(5532), 1129-1133. https://doi.org/10.1126/science.1061457

Ileperuma, O. A. (2020). Review of air pollution studies in Sri Lanka. Ceylon Journal of Science 49(3), 225-238. http://doi.org/10.4038/cjs.v49i3.7773

Imbulana, K. A. U. S., Wijesekera, N. T. S., \& Neupane, B. R (Eds.). (2006). Sri Lanka National Water Development Report. Ministry of Agriculture, Irrigation and Mahaweli Development and Environment, UN-WWAP, UNESCO and University of Moratuwa.

Jayawardena, D. (1984). The present status of the development of mineral resources in Sri Lanka. Journal of National Science Council Sri Lanka, 12(1), 53-69. http://doi.org/10.4038/jnsfsr. v12i1.8372

Jones, B. L., Unsworth, R. K. F., Udagedara, S.\& Cullen-Unsworth, L. C. (2018). Conservation concerns of small-scale fisheries: By-catch impacts of a shrimp and finfish fishery in a Sri Lankan lagoon. Frontiers in Marine Science, 5(52). https://doi.org/10.3389/fmars.2018.00052

Joseph, L. (2004). National report of Sri Lanka on the formulation of a transboundary diagnostic analysis and strategic action plan for the Bay of Bengal large marine ecosystem programme [Unpublished report].

Katupotha J. (1993). Local sea level indicators for investigation of coastal evolution in Sri Lanka during the past 20,000 years. Proceedings of the Symposium on Quaternary coastal evolution models, processes, and local to global factors, Belgium, 78-81. 
Kularatne, R. K. A. (2014). Suitability of the coastal waters of Sri Lanka for offshore sand mining: A case study on environmental considerations. Journal of Coastal Conservation, 18(3), 227-247. https://doi.org/10.1007/s11852-014-0310-7

Kulasooriya, S. A. (2021). Organic agriculture: A sustainable, eco-friendly system of crop production. Ceylon Journal of Science, 50(2), 101-102. http://doi.org/10.4038/cjs.v50i2.7870

Kumarasinghe, A., Pradeep, W. A. A. D. G., Peabotuwage, P. I. K., Wickramaarachchi, R. G. A. T. S., Somarathne, S., Perera, B. N. H., Abeyawardene, U. T. I., Wijesinghe, M. R., \& Karunarathna, D. M. S. S. (2013). An attempt to reduce impacts of limestone quarries through biodiversity assessment and translocation: a case study at the Holcim limestone quarry site in Puttalam Sri Lanka. Asian Journal of Conservation Biology, 2(1), 3-20.

McLoughlin, S. (2001). The breakup history of Gondwana and its impact on pre-Cenozoic floristic provincialism. Australian Journal of Botany, 49(3), 271-300. https://doi.org/10.1071/BT00023

Ministry of Environment. (2012). The national red list 2012 of Sri Lanka; Conservation status of the fauna and flora.

Ministry of Fisheries. (2020). Fisheries statistics 2020.

Ministry of Fisheries and Aquatic Resources Development. (2020). Fisheries statistics 2019.

Ministry of Irrigation Water Resources Management. (2018). Strategic environmental assessment for water resource development and irrigation development in Sri Lanka.

Ministry of Mahaweli Development and Environment. (2016). National biodiversity strategy and action plan 2016-2022. Biodiversity Secretariat, Ministry of Mahaweli Development and Environment.

Miththapala, S. (2013). Lagoons and estuaries. Coastal Ecosystems Series (Vol 4). IUCN Sri Lanka.

Panabokke, C. R. (1996). Soils and agro-ecological environments of Sri Lanka. NARESA.

Panabokke, C. R., \& Perera, A. P. G. R. L. (2005). Groundwater resources of Sri Lanka. Water Resources Board.

PEC (2019) Report on Sustainable Sri Lanka 2030 Vision and Strategic Path. Presidential Secretariat of Sri Lanka, Colombo. 315pp. http://www.presidentsoffice.gov.lk/wp-content/uploads/2019/05/ Final-v2.4-Typeset-MM-v12F-Cov3.pdf.

Piyadasa, R. U. K. (2011). River sand mining and associated environmental problems in Sri Lanka. Sediment Problems and Sediment Management in Asian River Basins (IAHS Publication 349, pp 148-153).

Prakash, T. G. S. L., Wijeratne, A. L., \& Fernando, P. (2020). Human-Elephant Conflict in Sri Lanka: Patterns and Extent. Gajah, 51,16-25.

Premathilake, R. (2006). The emergence of early agriculture in the Horton Plains, central Sri Lanka: Linked to late Pleistocene and early Holocene climatic changes. Pragdhara, 18, 91-104. 
Ramsar. (2021). Sites number and area by year: Sri Lanka. Retrieved from https://rsis.ramsar.org/ ris-search/?f[0]=regionCountry_en_ss\%3ASri+Lanka\&pagetab $=2$

Samarakoon, J., \& Samarawickrama, S. (2012). An appraisal of challenges in the sustainable management of the micro-tidal barrier-built estuaries and lagoons in Sri Lanka. IUCN Sri Lanka.

Samarasinghe, D. J. S., Wikramanayake, E. D., Jayakody, S., Fernando, S., Gunawardana, J., \& Braczkowski, A. (2021). A biodiversity hotspot in turmoil: Doing away with circular 5/2001 could have catastrophic consequences for Sri Lanka's forests. Conservation Science and Practice, 3(8), e466. https://doi.org/10.1111/csp2.466

Schumacher, E. F. (1973). Small is beautiful: Economics as if people mattered. Blond and Briggs.

SLPP Manifesto (2019) https://gota.lk/sri-lanka-podujana-peramuna-manifesto-english.pdf

Silva, E. I. L., Katupotha, J., Amarasinghe, O., Manthrithilake, H., \& Ariyaratna, R. (2013). Lagoons of Sri Lanka: From the origins to the present. International Water Management Institute (IWMI).

Silva, E. I. L. \& Silva, E. N. S. (2016). Hand book on small hydropower development and environment: A case study on Sri Lanka. Water Resources Science and Technology (WRST).

Subasinghe, H. C. S., Ratnayake, A. S. \& Sameera, K. A. G. (2021). State-of-the-art and perspectives in the heavy mineral industry of Sri Lanka. Mineral Economics, 34, 427-439. https://doi. org/10.1007/s13563-021-00274-3

Tanaka, N., Sasaki, Y., \& Mowjood, M. I. M. (2006). Effects of Sand Dune and Vegetation in the Coastal Area of Sri Lanka at the Indian Ocean Tsunami. Advances in Geosciences, 6, 149-160.

United Nations Educational, Scientific and Cultural Organization. (2021a). Sri Lanka. http://whc. unesco.org/en/statesparties/LK

United Nations Educational, Scientific and Cultural Organization. (2021b). Biosphere resources: Sri Lanka. http://www.unesco.org/new/en/natural-sciences/environment/\%20ecological-sciences/ biosphere-reserves/asia-and-the-pacific/sri-lanka/

The World Bank. (2021). Renewable internal freshwater resources per capita (cubic meters). https:// data.worldbank.org/indicator/ER.H2O.INTR.PC

World Forum on Natural Capital. (2021). What is natural capital? https://naturalcapitalforum.com/ about/ 